\title{
N91-19187
}

\section{AlGaAs Top Solar Cell for Mechanical Attachment in a Multi-Junction Tandem Concentrator Solar Cell Stack*}

\author{
L.C. DiNetta, M.H. Hannon, and J.B. McNeely \\ AstroPower, Inc. \\ Newark, DE \\ A.M. Barnett \\ University of Delaware \\ Newark, $D E$
}

\section{Introduction}

The theoretical limits for the $\mathrm{AlGaAs} / \mathrm{Si}$ tandem stack were determined using a solar cell model by Nell [ref. 1] based on tabulated standard spectra, the fit of experimentally achieved open-circuit voltages, and the assumption of unit quantum efficiency. More recent work [ref. 2] indicates that Nell's model underestimates opencircuit voltages. Incorporating this change, a theoretical AM0 efficiency of $42.9 \%$ at 100 suns is predicted for the tandem stack. The $100 \times$ values were calculated by assuming a linear increase in short-circuit current values and scaling the remainder of the cell operating parameters in accord with the diode equation. The result of device modeling shown in Table I assumes a subbandgap transparency of $100 \%$.

Shown in Figure 1 are iso-efficiency curves for various bandgap combinations. The curves indicate that there are a wide range of acceptable bandgap combinations within a given performance window.

A value of $95 \%$ transparency to sub-bandgap photons was used in the prediction of the "best case" performance. For direct-bandgap materials, predictions were determined by reducing the open-circuit voltage, short-circuit current, and fill factor to $96 \%, 91 \%$, and $96 \%$, respectively, of their theoretical limits. Indirect bandgap material reductions are correspondingly $91 \%, 96 \%$, and $96 \%$, respectively [ref. 3]. This permits stack performance predictions for the various combinations of top and bottom solar cell bandgaps. Performance of the "best case" AlGaAs top solar cells with 1.93 and $1.80 \mathrm{eV}$ bandgaps on silicon bottom solar cells are listed in Table II. The "best case" performance of the individual solar cells assumes no reflective losses or grid obscuration. However, the current generated by the bottom solar cell is limited by the bandgap of the top solar cell and reduced further by the transparency of the top solar cell to sub-bandgap photons.

*The work was supported in part by NASA Lewis Research Center under contract NAS3-25570. 
Four-terminal MSMJ tandem stack assemblies appear to be the best short term method to a $30 \%$ commercially available solar cell as demonstrated by recent results at AstroPower and elsewhere. Modeling of a four terminal stack of AlGaAs on InGaAsP indicates that it will be possible to achieve efficiencies of greater than $35 \%$. InGaAsP also has the added advantage of greater radiation hardness when compared to silicon. Predictions of this stack appear in Table III.

The next logical step in the development of high efficiency solar converter systems is the goal of $40 \%$ overall conversion efficiency. Table IV demonstrates the results of our modeling utilizing materials which are being developed at this facility. The predicted efficiencies include losses and are "best case" examples, not theoretical maximum values.

\section{Results}

The top solar cell is fabricated on a thick AlGaAs substrate that is i) highly transparent, ii) sufficiently rugged so as not to require additional support during subsequent processing, and iii) utilizes existing process technology. Liquid phase epitaxial growth techniques are employed for materials fabrication. When compared to MBE and MOCVD, the LPE technique has demonstrated higher quality AlGaAs material. Li [ref. 4] has reported that AlGaAs layers prepared by LPE have lower defect density than those prepared by other techniques. Minority carrier lifetimes of AlGaAs for LPE grown material are larger than for MOCVD grown material as reported by Ahrenkiel and Dunlavy [ref. 5]. Both Saletes [ref. 6] and Mayet [ref. 7] have reported material problems with compositions near the $1.93 \mathrm{eV}$ direct-indirect energy bandgap cross-over region. Lewis and coworkers [ref. 8], on the other hand, have reported excellent devices at this bandgap. Regardless, our modeling indicates that the tandem stack efficiency is virtually unchanged with a top solar cell bandgap between 1.93 and $1.80 \mathrm{eV}$.

Utilizing an AlGaAs substrate that has a bandgap equal to or greater than the active device region of the solar cell provides the required high transparency. The reflection plus transmission curves of the substrate layer with a wider bandgap than the active layer and the active layer grown on the substrate layer appear in Figure 2.

The base and emitter can be tuned to any desirable energy bandgap between 1.43 $\mathrm{eV}$ and $1.93 \mathrm{eV}$, the direct-indirect crossover point for the Al-Ga-As mixed crystal system. Typically, a 10 -micron base and a 0.1 micron emitter are used with a graded bandgap window layer to reduce surface recombination. The graded window layer also improves the current collection since i) a field exists to attract the minority carriers to the junction, and ii) a gradual change in index of refraction minimizes reflection at the AlGaAs window/emitter interface [ref. 7].

The devices fabricated are $\mathrm{p} / \mathrm{n}$ structures. The solar cell is a $4 \mathrm{~mm}$ diameter active area design based on a $5 \mathrm{~mm} \times 5 \mathrm{~mm}$ die. Ohmic contacts are accomplished 
through the deposition of conducting alloys to the top and bottom surfaces. Presently, the contact scheme consists of Au-Ge compounds for the $\mathrm{n}+$ contacts and $\mathrm{Au}-\mathrm{Zn}$ compounds for the $\mathrm{p}+$ contacts.

An "AlGaAs filter" was fabricated to study the transparency of the material to sub-bandgap photons. The filter consisted of a $1.9 \mathrm{eV}$ active layer on a selfsupporting $\mathrm{Al}_{0.7} \mathrm{Ga}_{0.3} \mathrm{As}$ layer of approximately 120 microns thickness. Quantum efficiency curves of a silicon solar cell with and without the filter in place are shown in Figure 3. Calculating the transparency of the "AlGaAs filter" is straight forward. First, a ratio of the filtered bottom cell light generated current to the unfiltered light generated current is calculated.

Ratio $_{\mathrm{Jl}}=\mathrm{Jl}_{\text {filtered }} / \mathrm{Jl}_{\text {unfiltered }}$

Then, the same rationale is applied to the photon flux assuming unit quantum efficiency of the bottom cell.

Ratio $_{\Phi}=\Phi_{\text {sub-bandgap }} / \Phi_{\text {Silicon }}$

The transparency is calculated as:

Transparency $=$ Ratio $_{\mathrm{Jl}} /$ Ratio $_{\Phi}$

Results of this calculation yield a sub-bandgap transparency of $91 \%$ for the AM0 solar spectrum.

Detailed analysis of the $\mathrm{R}+\mathrm{T}$ measurement of the AlGaAs filter revealed that free-carrier absorption in the $\mathrm{AlGaAs}$ substrate was less than $2 \%$, and the remaining loss was purely reflective.

Quantum efficiency and current-voltage curves were employed to evaluate the quality of the AlGaAs solar cells. Growth conditions were changed to optimize the operation of the solar cell based on the results of these measurements. Parameters included junction depth and emitter doping, window thickness, base layer thickness and doping, and contact alloy time and temperature.

Characteristics of a wide bandgap solar cell are presented in Figures 4 and 5 . As can be seen from the external quantum efficiency measurement, there is a sharp band-edge demonstrating excellent material quality. This is supported further by the high fill factors yielded by this device.

A decrease in the quantum efficiency corresponding to an increase in aluminum content of the Al-Ga-As mixed crystal system has been reported [ref. 8]. With greater than $32 \% \mathrm{Al}$, there is a dramatic reduction in quantum efficiency and therefore a decrease in the solar cell performance. The operating characteristics of the $1.80 \mathrm{eV}$ AlGaAs concentrator solar cell are presented in Figures 6 and 7 . 
The internal quantum efficiency of the device is over $90 \%$ for much of the absorbed spectrum when allowance is made for the grid obscuration.

Results of the two best AstroPower AlGaAs solar cells to date and the predicted stack efficiencies are demonstrated in Table V. Silicon performance is projected based on $95 \%$ top solar cell transparency.

Performance of this stack configuration would be enhanced with a few basic refinements in fabrication. Substitution of an anti-obscuration, prismatic cover with a matched grid structure will reduce contact shading to zero. With these improvements the AlGaAs concentrator solar cells will yield the predicted efficiencies shown in Table VI.

The approach used to fabricate a free-standing AlGaAs top concentrator cell, useful for concentrator systems, was to grow a 50 micron thick graded base layer on the GaAs substrate. After contacts are made to the AlGaAs device on the GaAs substrate, the GaAs is etched away under the illuminated region of the AlGaAs device. This device structure is shown in Figure 8.

The method for substrate removal used to fabricate the above devices is an etch bath consisting of $\mathrm{H}_{2} \mathrm{O}_{2}, \mathrm{NH}_{4} \mathrm{OH}$, and EDTA added as a complexing agent. This etch exhibits a temperature dependent rate as can be seen in Figure 9. Excellent control can be exercised over the rate of etching by controlling the temperature: making it possible to remove the GaAs substrate quickly and at the same time continuing to maintain the selectivity of the etch.

A family of current-voltage curves was measured during each step in the fabrication process. No degradation of the solar cell operating characteristics, exhibited by device G-156 \#2, was observed during the processing of the device. Most AlGaAs solar cells possess excellent process survivability as shown in Figure 10. After this particular device was processed, the glass slide onto which it had been bonded with RTV silicone was found to have cracked and consequently the device was removed. During the removal the lead attachment which had been made to the front and back of the solar cell was inadvertently removed. The solar cell was retested and no cell degradation was exhibited by this device even after the abusive handling.

\section{Conclusion}

The AstroPower self-supporting, transparent AlGaAs top solar cell can be stacked upon any well-developed bottom solar cell for improved system performance. This is a unique approach to improve the performance and scale of space photovoltaic power systems. Mechanically stacked tandem solar cell concentrator systems based on the AlGaAs top concentrator solar cell can provide near term efficiencies of $36 \%$ (AM0, $100 \times)$. Possible tandem stack efficiencies greater than $38 \%(100 \times$, AM0) are feasible with a careful selection of materials. In a three solar cell stack, system efficiencies 
exceed $41 \%(100 \times$, AM0) . These device results demonstrate a practical solution for a state-of-the-art top solar cell for attachment to an existing, well-developed solar cell.

\section{References}

[ 1. ] M. E. Nell, and A. M. Barnett, IEEE Trans. Electron Devices, bf ED-34, 257.

[ 2.] P. H. Mauk, N. E. Terranova, and A. M. Barnett, To be published.

[ 3. ] A. M. Barnett, and J. S. Culik, 19th IEEE Photovoltaic Specialists Conference, 931, 1987.

[ 4.] Sheng S. Li, 15th IEEE Photovoltaic Specialists Conference, 1283, 1981.

[ 5.] R. K. Ahrenkiel, and D. J. Dunlavy, Journal of Vacuum Science and Technology, 7, 822, 1989.

[ 6.] A. Saletes, A. Rudra, P. Basmaji, J. F. Carlin, M. Leroux, J. P. Contour, P. Gibard and C. Verie, 19th IEEE Photovoltaic Specialists Conference, 124, 1987.

[ 7.] L. Mayet, M. Gavand, B. Montegu, and A. Laugier, 20th IEEE Photovoltaic Specialists Conference, 597, 1988.

[ 8.] C. R. Lewis, H. C. Hamaker and R. T. Green, Journal of Electronic Materials, 16, 1987.

[ 9.] A. W. Blakers, A. Wang, A. M. Milne, J. Zhao, X. Dai and M. A. Green, 4th International Photovoltaic Science $\&$ Engineerinq Conference, Sydney, Australia, 1989. 


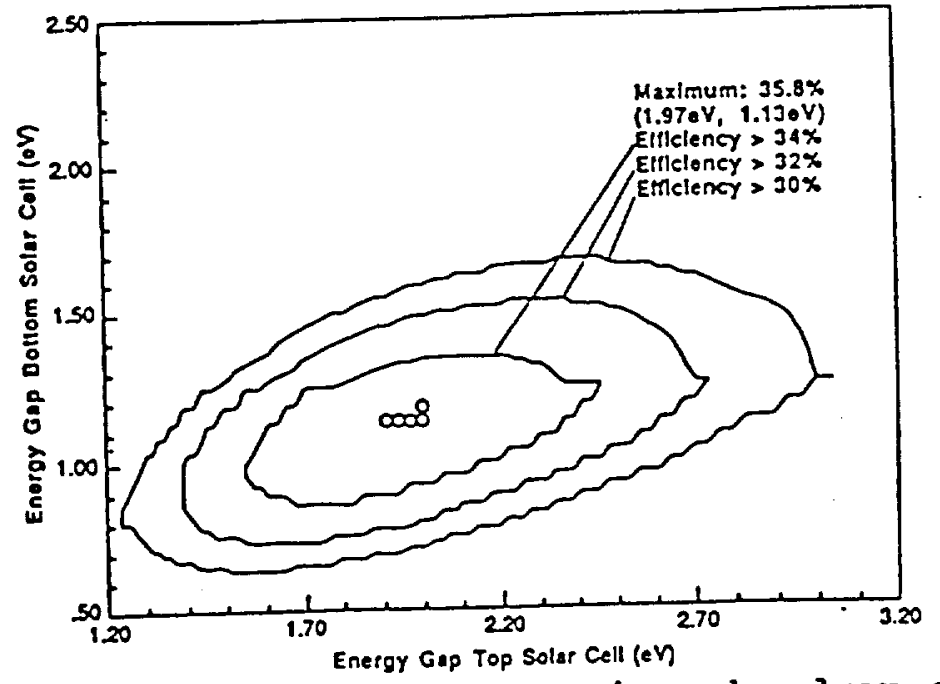
Figure 1. Iso-efficiency curves for various bandgap combinations
(AMO, IX) [2].

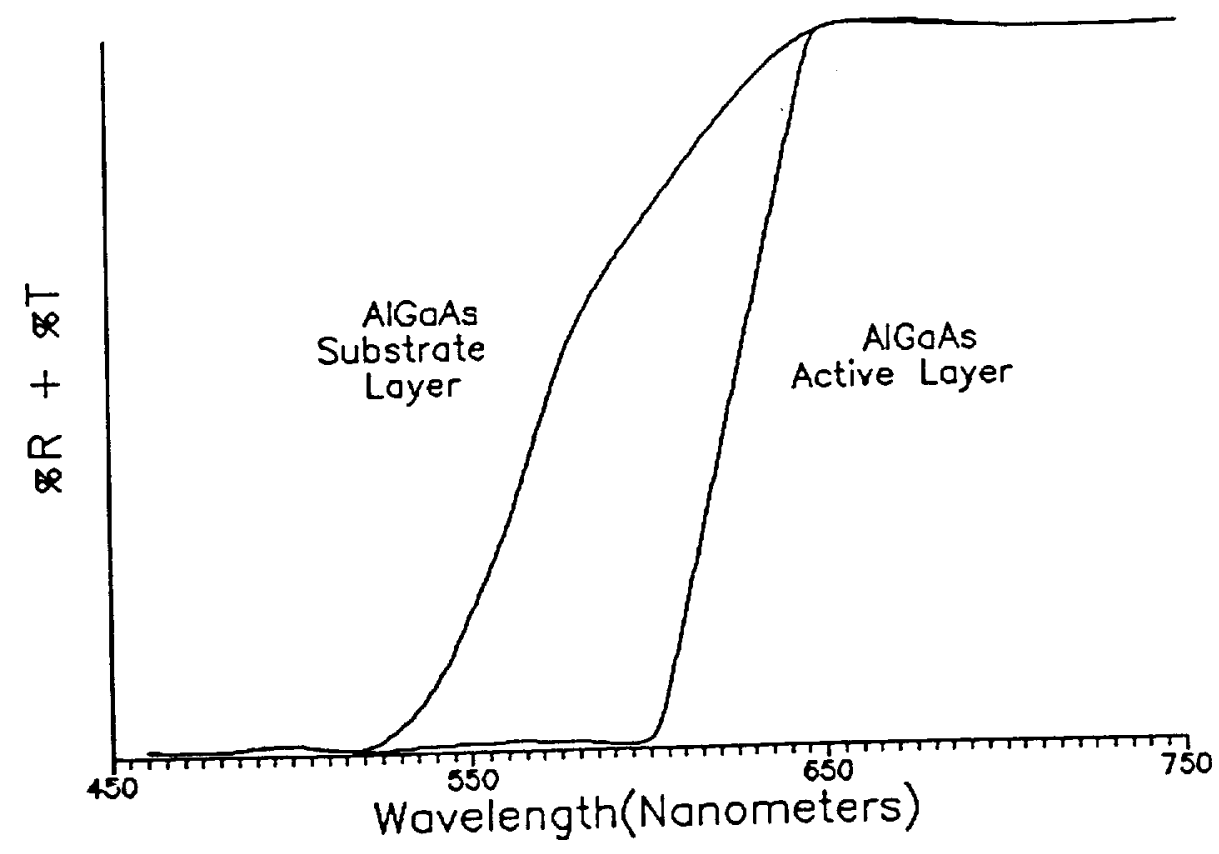
Figure 2. $\begin{aligned} & \text { Reflection + transmission of active layer on substrate } \\ & \text { layer. }\end{aligned}$ 


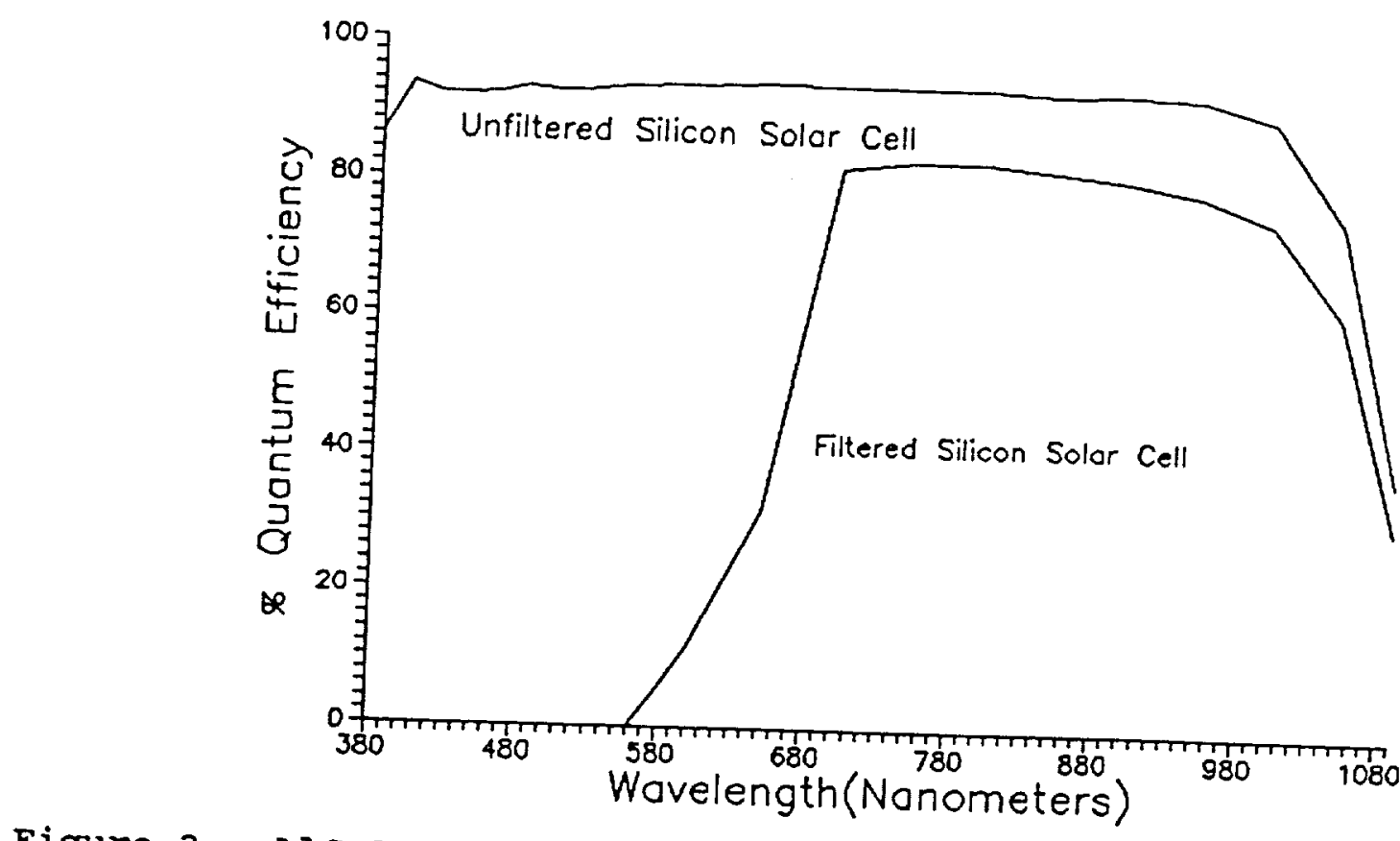

Figure 3. AlgaAs top solar cell transparency demonstrated by
placement over an existing cell.

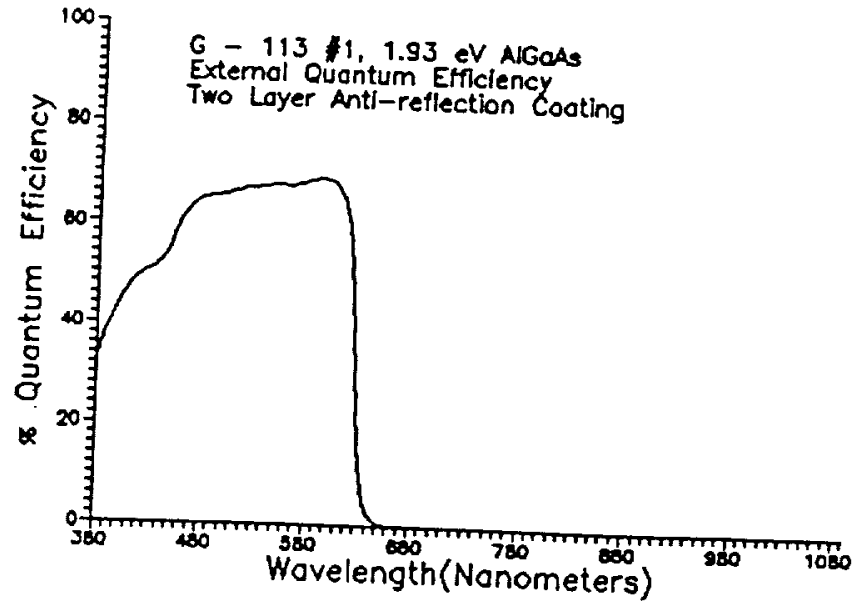

Figure 4. External quantum efficiency of $1.93 \mathrm{eV}$ AlGaAs solar cell with grid obscuration.

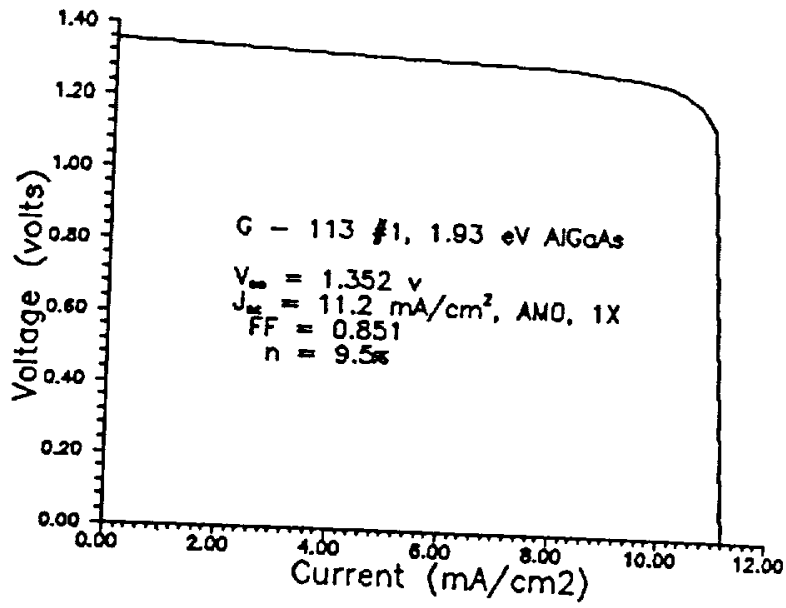

Figure 5. Operating characteristics of 1.93 eV AlGaAs solar cell with grid obscuration. 


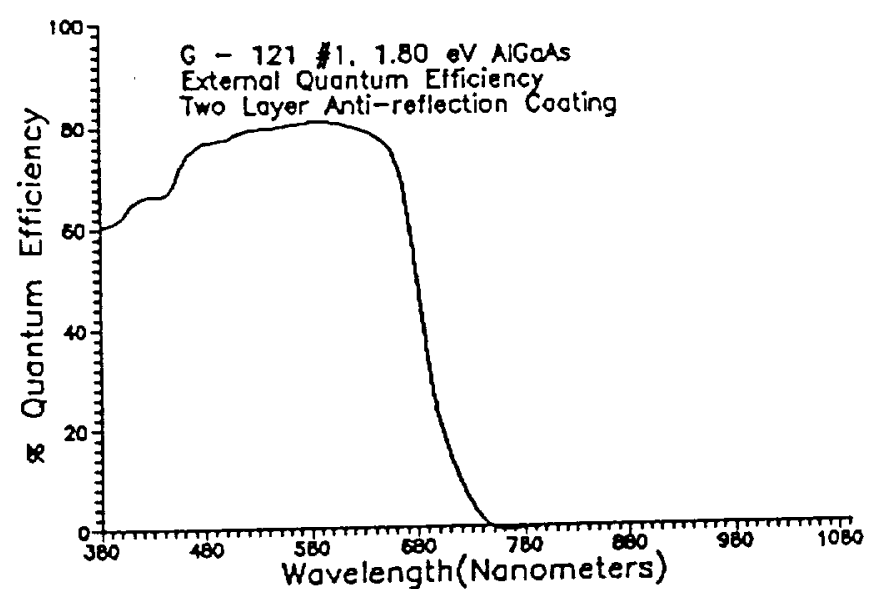

Figure 6. External quantum efficiency of a $1.80 \mathrm{eV}$ AlGaAs solar cell with grid obscuration.

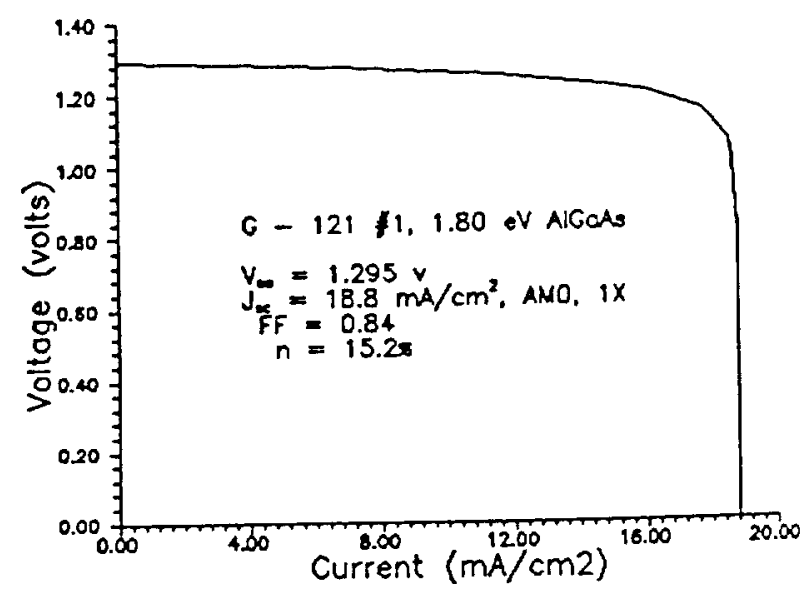

Figure 7.Operating characteristics of a $1.80 \mathrm{eV}$ AlGaAs solar cell with grid obscuration.

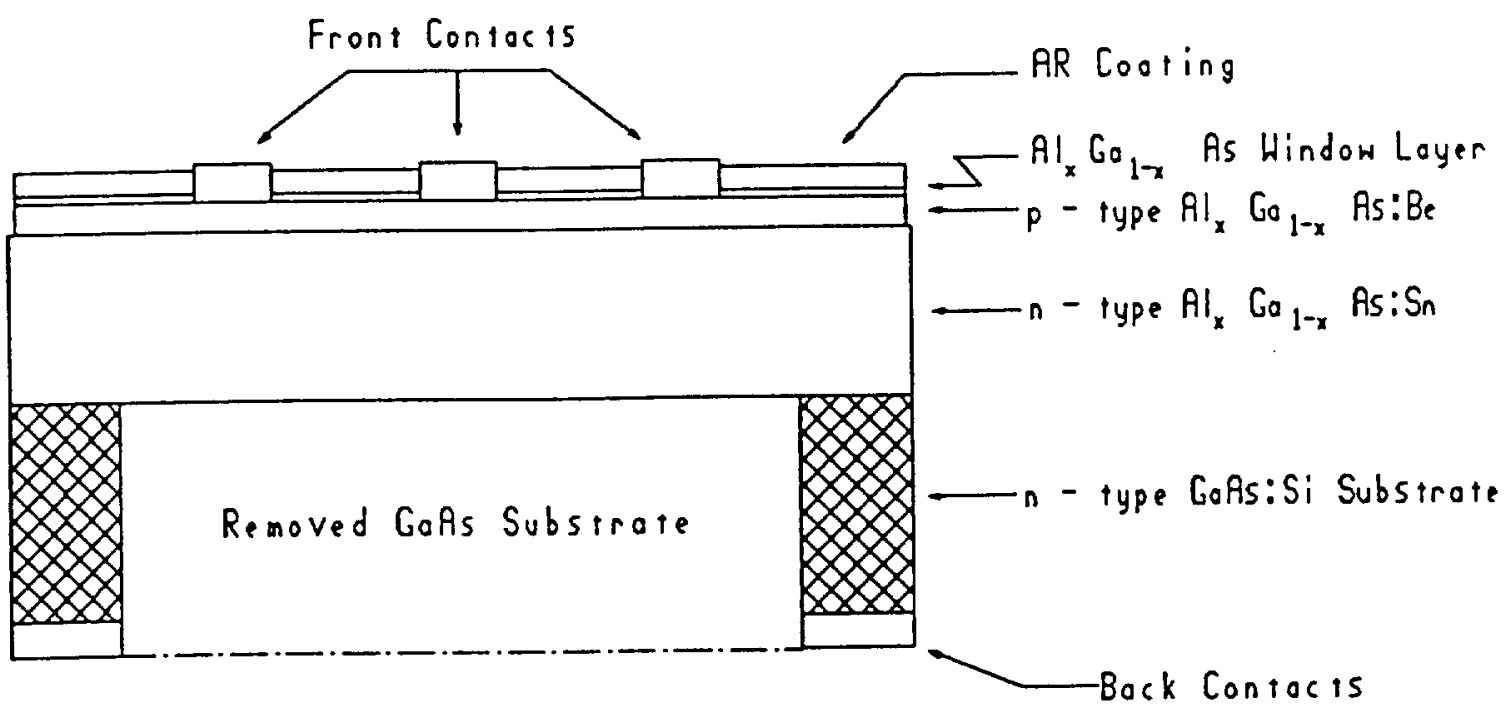

Figure 8. AlGaAs/AlGaAs on GaAs contact for concentrator systems. 


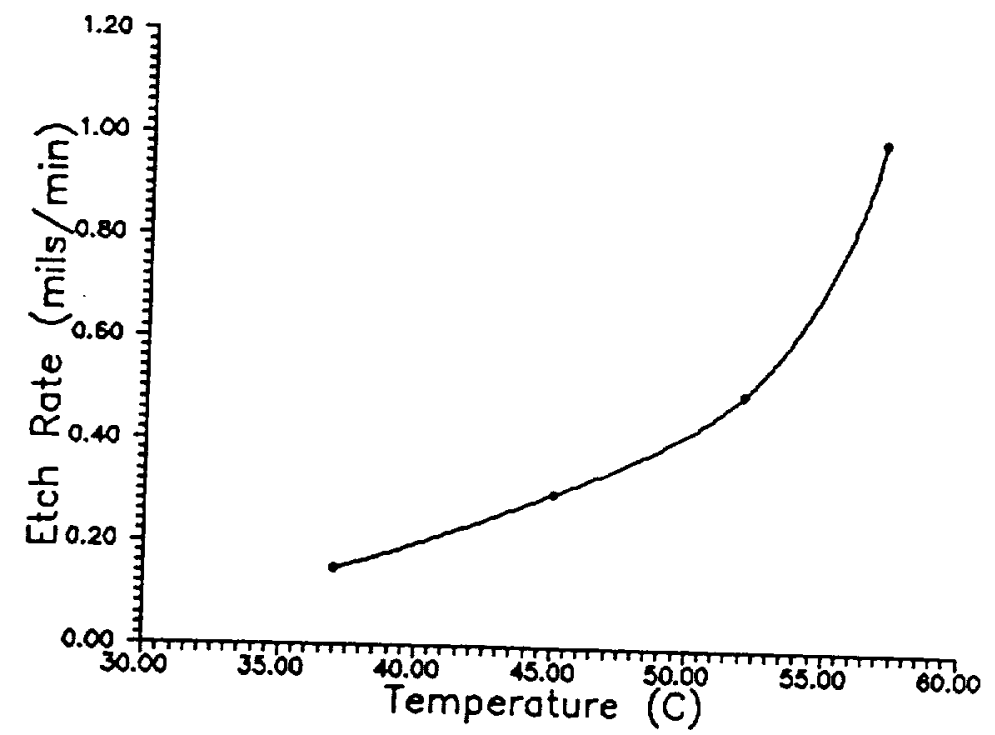

Figure 9. Etch-Rate vs. Temperature for a selective GaAs etch. 


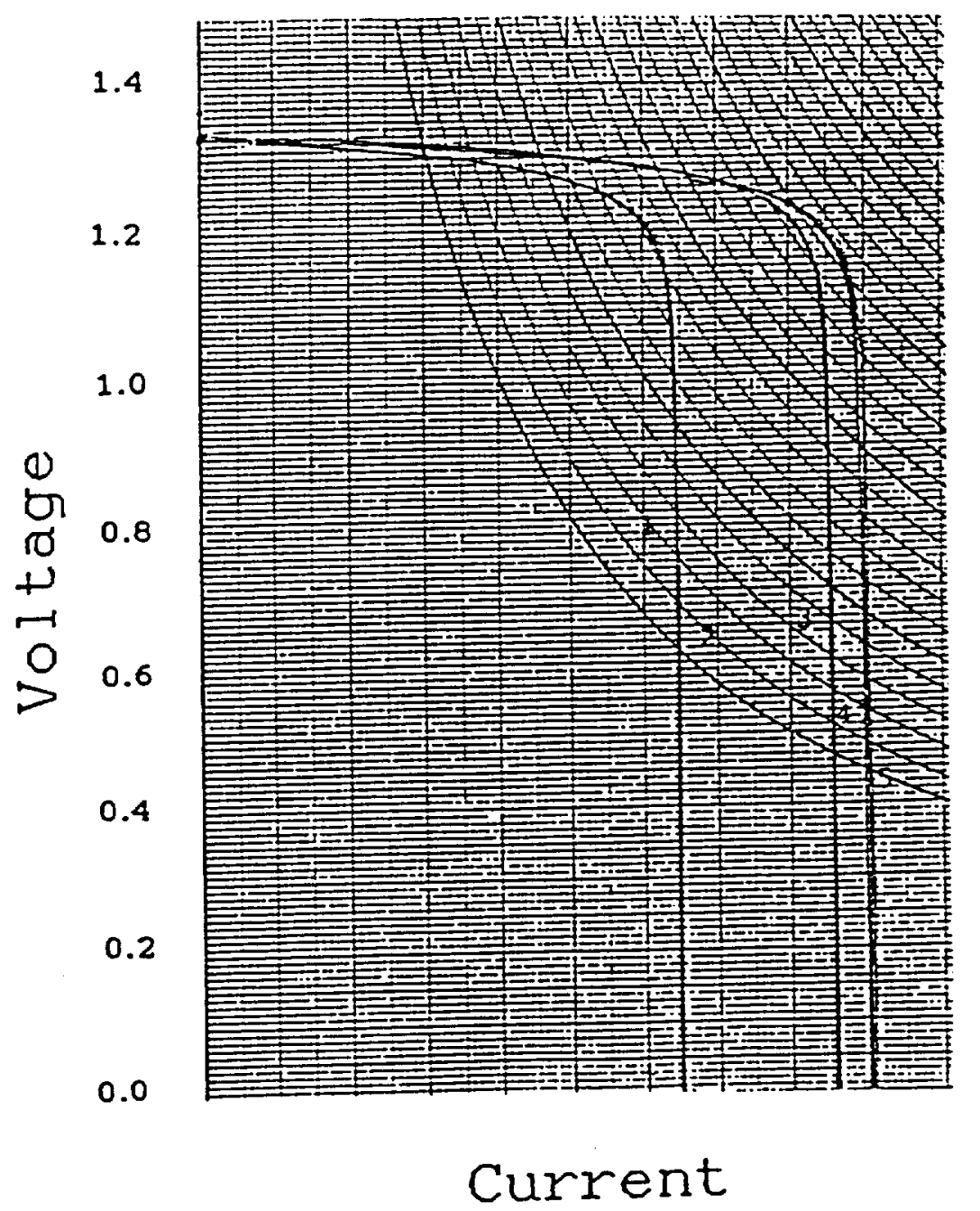

\begin{tabular}{|c|c|c|c|c|c|}
\hline CURVE & (volts) & $\left(\mathrm{mA} \mathrm{J}^{2}\right)$ & $\mathbf{F F}$ & $\begin{array}{l}\text { Effi: } \\
(x)\end{array}$ & CARENT \\
\hline $\begin{array}{l}1 \\
2 \\
3\end{array}$ & $\begin{array}{l}1.331 \\
1.329 \\
1.341\end{array}$ & $\begin{array}{l}6.93 \\
6.93 \\
9.08\end{array}$ & $\begin{array}{l}0.85 \\
0.85 \\
0.85\end{array}$ & $\begin{array}{l}5.81 \\
5.81 \\
7.67\end{array}$ & $\begin{array}{l}\text { Initial } \\
\text { Front lead attach } \\
\text { AR coating \& RTV bond to } \\
\text { glass superstrate }\end{array}$ \\
\hline 4 & 1.333 & 10.03 & 0.85 & 8.41 & $\begin{array}{l}\text { Gais substrate removed \& } \\
\text { back lead attach }\end{array}$ \\
\hline 5 & 1.333 & 10.03 & 0.85 & 8.41 & $\begin{array}{l}\text { removal of RIV and lead } \\
\text { attachwent }\end{array}$ \\
\hline
\end{tabular}




\section{Table I}

Predicted Theoretical Maximum Efficiency for

a Four-Terminal AlGaAs/Si Mechanical stack (AMO, $135 \mathrm{~mW} / \mathrm{cm}^{2}$ )

Material

$\frac{E_{g}}{(\mathrm{eV})} \quad \frac{\mathrm{Voc}}{(\mathrm{volts})} \quad \frac{\mathrm{Jsc}}{\left(\mathrm{mA} / \mathrm{cm}^{2}\right)} \quad \frac{F F}{\left(\frac{\mathrm{Eff}}{2}\right)} \frac{\operatorname{Eff}(100 \mathrm{X})}{(\%)}$

$\begin{array}{lllllll}\text { AlGaAs } & 1.93 & 1.588 & 21.55 & 0.91 & 23.0 & 24.7 \\ \text { Silicon } & 1.13 & 0.788 & 31.88 & 0.85 & 15.8 & 18.2\end{array}$

Four Terminal Stack Efficiency --> 38.8. 42.9

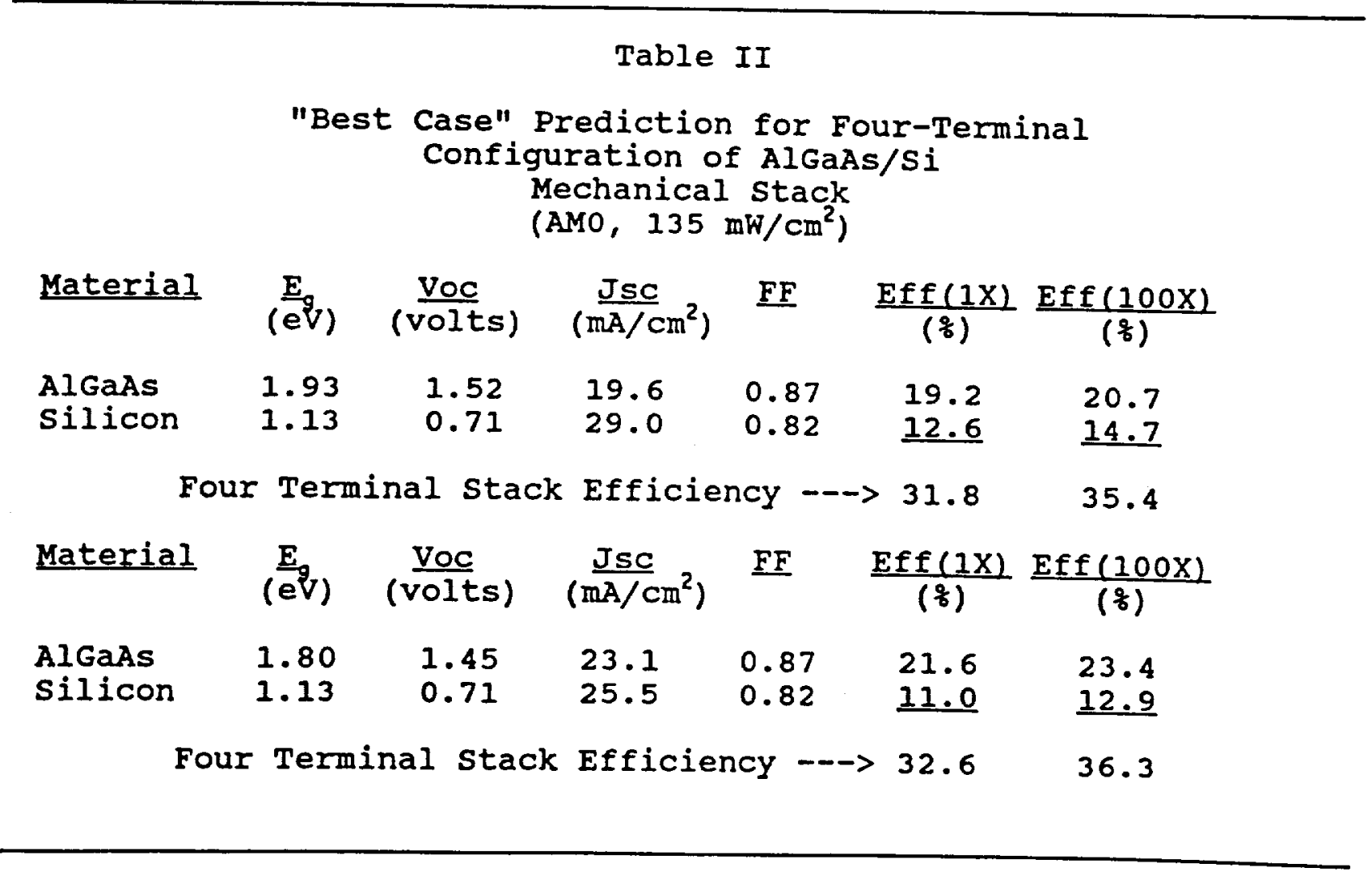


Table III
"Best Case" Prediction for Four-Terminal Configuration of AlGaAs/InGaAs? Mechanical Stack (AMO, $135 \mathrm{~mW} / \mathrm{cm}^{2}$ )

Material $\quad \frac{E g}{(\mathrm{eV})} \quad \frac{\mathrm{Voc}}{(\mathrm{volts})} \quad \frac{\mathrm{Jsc}}{\left(\mathrm{mA} / \mathrm{cm}^{2}\right)} \quad \frac{\mathrm{FF}}{(z)} \quad \frac{\operatorname{Eff}(1 \mathrm{X})}{\operatorname{Eff}(100 \mathrm{x})}$

$\begin{array}{lccccccc}\text { AlGaAs } & 1.80 & 1.450 & 23.1 & 0.87 & 21.6 & 23.4 \\ \text { InGaAsP } & 1.08 & 0.763 & 27.7 & 0.81 & 12.7 & 14.7 \\ & & & & & & & \\ & \text { Four Terminal stack } & \text { Efficiency } & --> & 34.3 & 38.1\end{array}$

\section{Table IV}

"Best Case" Prediction for Six-Terminal Configuration of AlGaAs/InP/InGaAsP Mechanical stack (AMO, $135 \mathrm{~mW} / \mathrm{cm}^{2}$ )

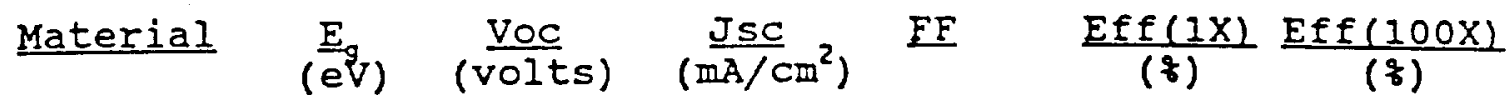

$\begin{array}{lllllll}\text { AlgaAs } & 1.93 & 1.520 & 19.6 & 0.87 & 19.2 & 20.7 \\ \text { InP } & 1.35 & 1.009 & 18.2 & 0.84 & 11.4 & 12.8 \\ \text { InGaAsP } & 0.89 & 0.519 & 22.4 & 0.77 & \underline{6.6} & \mathbf{8 . 1}\end{array}$

Six Terminal Stack Efficiency $\rightarrow-\rightarrow \quad 37.2 \quad 41.6$ 


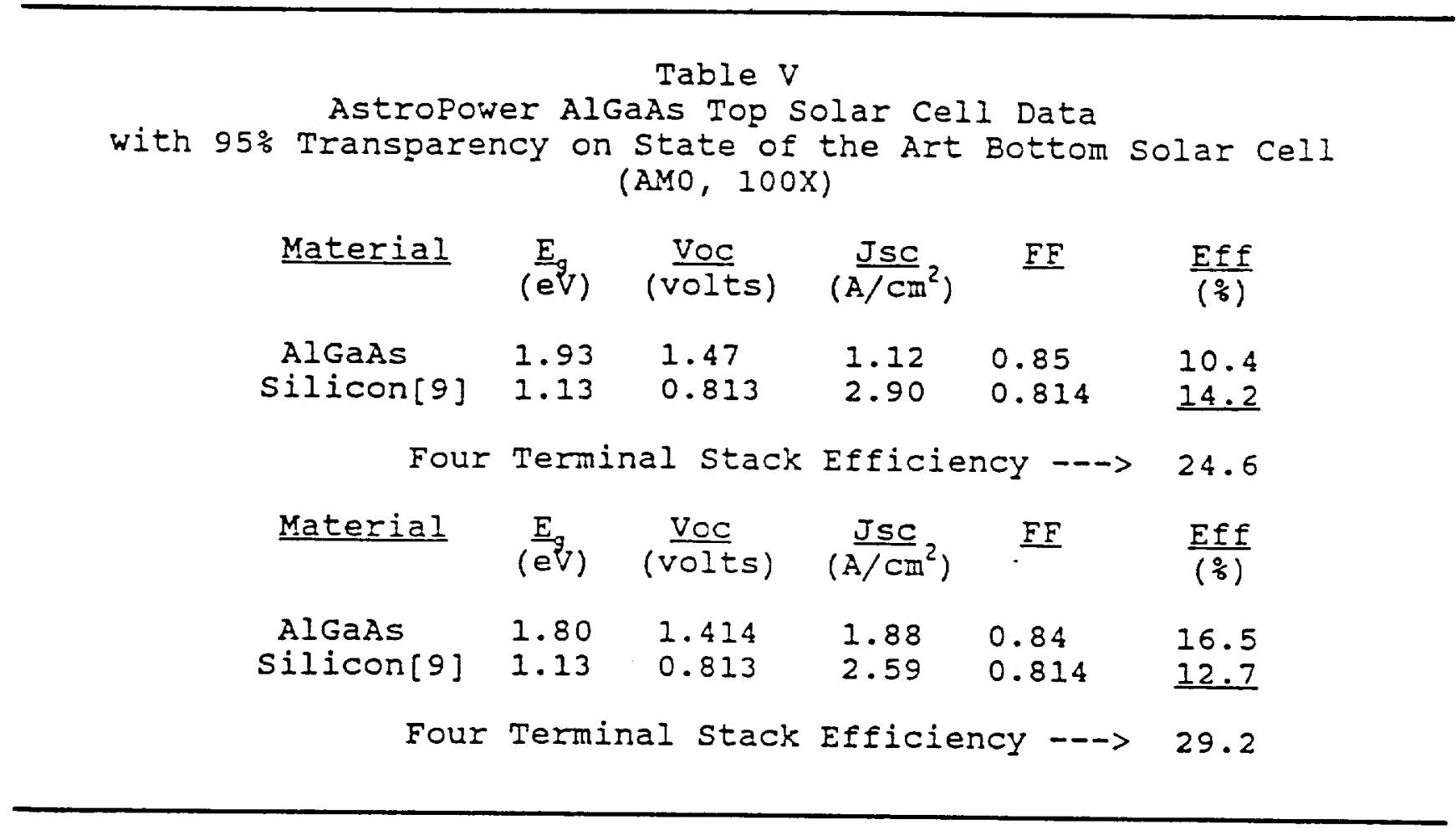

Table VI

Astropower AlGaAs Solar Cell Data Used for Predicted Performance of AlGaAs/Si Mechanical Stack with Anti-obscuration Prismatic Cover and $95 \%$ Transparency

(AMO, 100X)

$\begin{array}{cccccc}\text { Material } & \frac{E_{g}}{(\mathrm{eV})} & \begin{array}{c}\text { Voc } \\ \text { (Volts) }\end{array} & \frac{\mathrm{JSC}}{\left(\mathrm{A} / \mathrm{Cm}^{2}\right)} & \underline{F F} & \frac{\text { Eff }}{(\%)} \\ \text { AlGaAs } & 1.93 & 1.47 & 1.27 & 0.85 & 11.8 \\ \text { Silicon[9] } & 1.13 & 0.813 & 2.90 & 0.814 & 14.2\end{array}$

Four Terminal stack Efficiency $\rightarrow-\rightarrow \quad 26.0$ Material $\quad \frac{E}{(\mathrm{e} V)} \quad \frac{\text { Voc }}{(\text { Volts })} \quad \frac{\mathrm{JSC}}{\left(\mathrm{A} / \mathrm{cm}^{2}\right)} \quad \underline{F F} \quad \frac{\text { Eff }}{(\%)}$

$\begin{array}{cccccc}\text { AlGaAs } & 1.80 & 1.414 & 2.14 & 0.84 & 18.8 \\ \text { Silicon[9] } & 1.13 & 0.813 & 2.59 & 0.814 & 12.7\end{array}$

Four Terminal Stack Efficiency $-->\quad 31.5$ 